\title{
Sugar-beet fibre increases cholesterol and reduces bile acid excretion from the small bowel
}

\author{
BY ANNA MARIA LANGKILDE, HENRIK ANDERSSON \\ AND INGVAR BOSAEUS \\ Dept of Clinical Nutrition, The University of Göteborg, Sahlgrenska Hospital, \\ S-413 45 Göteborg, Sweden
}

(Received 2 March 1992 - Accepted 4 January 1993)

\begin{abstract}
The effect of addition of sugar-beet fibre to the diet on sterol excretion from the small intestine was studied in nine ileostomy subjects. A constant low-fibre diet was given in two $3 \mathrm{~d}$ periods with and without $32 \mathrm{~g}$ sugar-beet fibre/d in random order. Care was taken to minimize bacterial alteration of the ileostomy contents. The addition of sugar-beet fibre increased net cholesterol excretion by 52 (SE 9$) \%(P<0.01)$, from 294 (SE 99) to 451 (SE 124) $\mathrm{mg} / \mathrm{d}$, and decreased bile acid excretion by 26 (SE 15) \% $(P<0.01$ ), from 764 (SE 118) to 567 (SE 96) mg/d. The increased cholesterol and decreased bile acid excretion found with sugar-beet fibre addition is different from the pattern associated with fibre sources such as pectin and oat fibre. The interaction between dietary fibre and sterol metabolism may be mediated, therefore, by different mechanisms depending on the fibre source.
\end{abstract}

Dietary fibre: Bile acids: Faecal steroids: lleostomy

The effect of dietary fibre on lipid metabolism has been a subject of interest for a long time. Dietary fibre from different sources and of different composition has varying effects on serum cholesterol levels (for review, see Truswell \& Beynen, 1992). Fibre from most cereal sources, such as wheat bran, does not seem to lower serum cholesterol (Heaton \& Pomare, 1974; Jenkins et al. 1975; Truswell \& Kay, 1975) whereas viscous fibre such as pectin (Jenkins et al. 1975; Kay \& Truswell, 1977; Miettinen \& Tarpila, 1977; Judd \& Truswell, 1982) and certain gums (Jenkins et al. 1976) have been shown to have distinct hypocholesterolaemic properties. However, it has proved difficult to predict physiological effects from the chemical composition of high-fibre foods (Anderson et al. 1990).

The sugar-beet-fibre preparation used in the present study contains $730 \mathrm{~g}$ dietary fibre $/ \mathrm{kg}$, with a relatively large proportion of pectic substances and hemicellulose (Table 1). This composition would make a hypocholesterolaemic effect probable. In studies of the effects of sugar-beet fibre on serum cholesterol a small effect, about $5 \%$, has been found (Hagander et al. 1988, 1989; Israelsson, 1988) and in two recent studies on healthy individuals a 12 and $4.6 \%$ decrease in serum cholesterol respectively was found (Lampe $e t$ al. 1991; Tredger et al. 1991). A cholesterol-lowering effect has been found also in animal experiments (Johnson et al. 1990).

The cholesterol-lowering mechanism of dietary fibre is often ascribed to increased faecal bile acid excretion, demonstrated repeatedly for pectin and some gums (Kay \& Truswell, 1977; Miettinen \& Tarpila, 1977; Reddy et al. 1980). However, mixed high-fibre diets (Stasse-Wolthuis et al. 1979) and psyllium (Plantago ovata) husk supplementation (Abraham \& Mehta, 1988) produced no change in faecal bile acid excretion but a reduction in serum cholesterol. The addition of beans (Phaseolus vulgaris) caused a decrease in bile acid excretion accompanied by a clear hypocholesterolaemic effect (Anderson et al. 1984) 
Table 1. Composition of the sugar-beet-fibre preparation Fibrex $x^{(\mathbb{B}}$ (Typical proximate analysis $(\mathrm{g} / \mathrm{kg})$ provided by Swedish Sugar Co., Arlöv, Sweden)

\begin{tabular}{lc}
\hline Dietary fibre, total & 730 \\
Pectic substances and hemicellulose & 510 \\
Cellulose & 180 \\
Lignin & 40 \\
Protein $(\mathrm{N} \times 6.25)$ & 100 \\
Sucrose & $30-40$ \\
Minerals & $30-40$ \\
Fat & 3 \\
Water & 100 \\
\hline
\end{tabular}

and bagasse showed an increased bile acid excretion but no effect on serum cholesterol (Walters et al. 1975; McLean Baird et al. 1977). In these studies cholesterol excretion was not measured.

It seems logical to assume that the mechanisms behind the increased sterol excretion which are suggested to decrease serum cholesterol could be revealed only by careful measurements of bile acid and also of cholesterol excretion. Conventional sterol balance studies have, however, low precision due to variable large bowel transit time and varying bacteriological degradation of sterols (Bosaeus \& Andersson, 1990). These problems can be mainly overcome by using the ileostomy model where the ileostomy bags are changed every $2 \mathrm{~h}$ and the samples immediately deep-frozen (Sandberg et al. 1981). The low day-to-day variation makes such short-term studies feasible with high precision (Tornquist et al. 1986).

In the present study we have investigated the effect of adding sugar-beet-fibre to a mixed solid diet on sterol excretion in man. We report here the short-term effects on bile acid and cholesterol excretion in ileostomy subjects.

\section{METHODS}

\section{Subjects}

Nine subjects (five women, four men) with a mean age of 40 (range 24-64) years and an average weight of 76.4 (range $54.6-113$ ) $\mathrm{kg}$ volunteered for the study. The subjects were previously proctocolectomized for ulcerative colitis and had well established conventional ileostomies. The ileostomies functioned properly and the volumes of excreta were within the normal range without the use of drugs. All patients were in good health, without symptoms or signs of small bowel inflammation, ileostomy dysfunction, liver, renal or thyroid disease. Informed consent was obtained from all participants and the study protocol was approved by the Ethical Committee of Sahlgren's Hospital.

\section{Protocol}

During two $3 \mathrm{~d}$ periods each subject consumed a basal low-fibre diet. In one period $32 \mathrm{~g}$ sugar-beet-fibre concentrate (Fibrex ${ }^{\mathbb{B}}$; Swedish Sugar Co., Arlöv, Sweden)/d was added to the diet. Diet periods were selected in random order. The first day of each $3 \mathrm{~d}$ period was a run-in day and during the following $2 \mathrm{~d}$ ileostomy effluents were collected for analysis (see p. 760).

The sugar-beet-fibre concentrate, Fibrex ${ }^{(\mathbb{B}}$, is composed mainly of pectic substances, hemicellulose and cellulose (Table 1). The polysaccharide components of Fibrex ${ }^{\mathbb{B}}$ are shown in Table 2. Glucose is derived virtually only from cellulose, which is totally insoluble. Part of the arabinose content and xylose come from the hemicellulose. 
Table 2. The polysaccharide components of the sugar-beet-fibre preparation Fibrex ${ }^{\circledR *}$ (relative distribution of anhydrounits; \%)

\begin{tabular}{lr}
\hline Glucose & 25.1 \\
Galactose & 6.9 \\
Mannose & 1.3 \\
Rhamnose & 2.5 \\
Xylose & 2.0 \\
Arabinose & $25 \cdot 1$ \\
Galacturonic acid & 31.3 \\
Acetic acid & 3.8 \\
Methyl alcohol & 1.3 \\
Ferulic acid & 0.7 \\
\hline
\end{tabular}

* Swedish Sugar Co., Arlöv, Sweden.

Table 3. Menu for the basal low-fibre diet

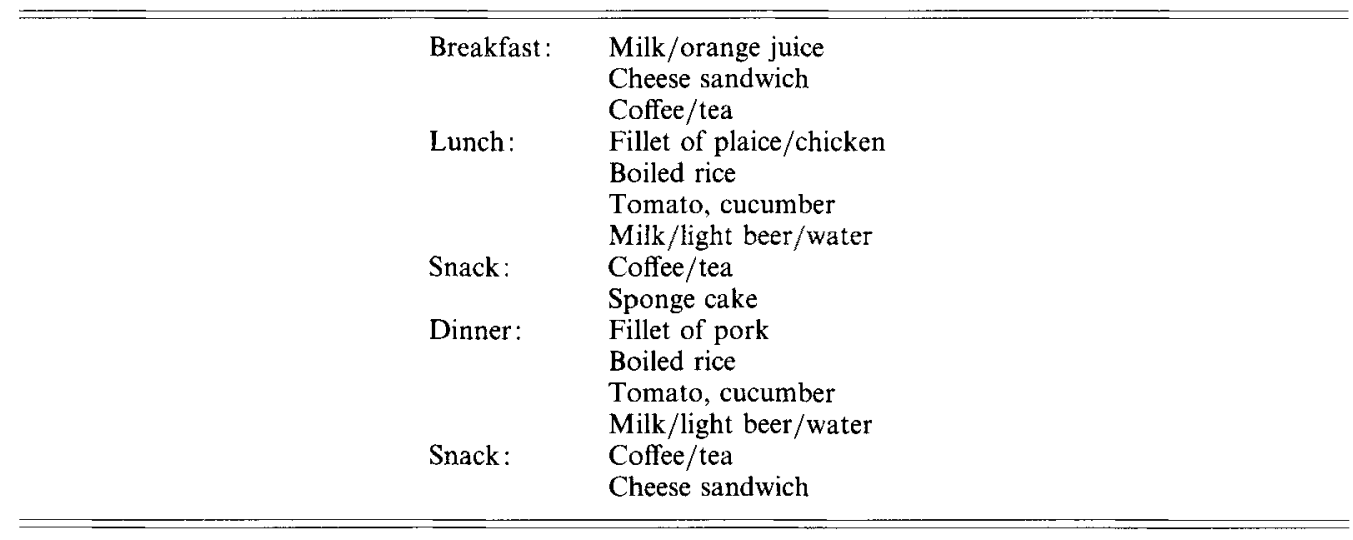

Rhamnose is more or less evenly distributed within the galacturonic backbone of the pectin (Rombouts \& Thibault, 1986). The rest of the carbohydrates originate from pectin. At least $35 \%$ of the pectic substances and hemicellulose $\left(20 \%\right.$ of the Fibrex ${ }^{\circledR}$ preparation) are soluble in vitro (Asp, 1990). About $50 \%$ of the uronic acid carboxyl groups are methylated. Acetyl groups are also attached to the galacturonic acid residues, half of the residues carry one acetyl group at position 2 or 3 (Keenan et al. 1985). Feruloyl groups are attached to the end of some of the neutral sugar side-chains.

\section{Diets}

The experimental diets were made from conventional food items and care was taken that they should be palatable and acceptable to the subjects. The menu and the mean nutritional values for the basal low-fibre diet are given in Tables 3 and 4 . The values for energy, fat and protein were obtained by analysis and the values for carbohydrates were calculated from Swedish Food Composition tables (National Food Administration, 1988).

Before the study records of diet and activity were made for each subject to enable adjustment of the basal diet to each subject's energy needs. Alternatives were available for the lunch dish and the beverages. Adjustment of the energy content was made by varying the servings of bread and rice. To assure compliance to the diet and to check the selected amount of food, a test day with the basal diet preceded the study. The subject's choice was 
Table 4. Diet composition

(Mean values and standard deviations)

\begin{tabular}{|c|c|c|c|c|}
\hline & \multicolumn{2}{|c|}{ Basal diet } & \multicolumn{2}{|c|}{ Basal diet +32 g Fibrex } \\
\hline & Mean & SD & Mean & SD \\
\hline Energy $(\mathrm{MJ} / \mathrm{d})$ & $10 \cdot 75$ & $2 \cdot 4$ & $11 \cdot 05$ & $2 \cdot 4$ \\
\hline Fat $(g / d)$ & 78 & 19 & 81 & 14 \\
\hline Protein (g/d) & 100 & 21 & 100 & 22 \\
\hline Carbohydrates $(\mathrm{g} / \mathrm{d})$ & 294 & 70 & 302 & 77 \\
\hline Fibre, total $(\mathrm{g} / \mathrm{d})$ & $4 \cdot 3$ & $1 \cdot 1$ & 27.8 & $3 \cdot 6$ \\
\hline Fibre from Fibrex ${ }^{(g / d)}$ & 0 & & $23 \cdot 4$ & 40 \\
\hline Cholesterol $(\mathrm{mg} / \mathrm{d})$ & 288 & 40 & 315 & 40 \\
\hline
\end{tabular}

* Swedish Sugar Co., Arlöv, Sweden.

then kept constant throughout the study. During one $3 \mathrm{~d}$ period $32 \mathrm{~g}$ sugar-beet-fibre product/d was added. Sugar-beet fibre was added partly by incorporation in bread and sponge cake and partly as doses divided between the meals, as breakfast cereal or mixed in the rice with the main meals. An average of $15 \mathrm{~g}$ Fibrex ${ }^{\mathbb{B}} / \mathrm{d}$ was incorporated in bread and sponge cake which could be made palatable with a sugar-beet-fibre level of 68 and $49 \mathrm{~g} / \mathrm{kg}$ respectively.

All food items were purchased in batches before the study and the same batch was used for all subjects. The food was prepared in advance in the metabolic ward kitchen. Individual portions of the meals were stored at $-18^{\circ}$ and were thawed and heated on the day of consumption. The subjects had all their meals at the metabolic ward and they were carefully instructed not to leave any food or to eat anything but the food served at the metabolic ward. If there were still any leftovers they were collected for analysis.

A duplicate portion of the diet of each patient, from each period, was collected for analysis, homogenized and freeze-dried to constant weight.

\section{Collection of ileostomy contents}

Ileostomy contents were collected during the last $2 \mathrm{~d}$ in each period. To avoid bacterial degradation the ileostomy bags were changed every $2 \mathrm{~h}$ during the day from 07.00 hours until retiring at night. The same bag was kept during the night. Each bag was immediately frozen on dry ice in a portable Dewar vessel (Karlsruher Glasteknik, Karlsruhe, Germany). The bags were weighed, stored at $-20^{\circ}$ and freeze-dried to constant weight. The contents from each $24 \mathrm{~h}$ period ( 07.00 hours-07.00 hours) were pooled and homogenized for analysis.

\section{Analytical methods}

All analyses were made in duplicate. Fat in ileostomy contents was determined according to van der Kamer (1949). Bile acids and neutral steroids in ileostomy contents were analysed as previously described (Bosaeus et al. 1986). Briefly, internal standards 5- $\alpha-$ cholestane (Sigma Chemical Co., St Louis, MO, USA) and hyodeoxycholic acid (Serva Feinbiochemika, Heidelberg, Germany) were added, ileostomy excreta were saponified and bile acids deconjugated by alkaline hydrolysis. After extraction and methylation with 2,2dimethoxypropane, acid and neutral sterols were separated and quantified by GLC using a Varian 3700 system (Varian Instruments, Palo Alto, CA, USA). A 12.5 m SE-54 capillary column was used, with $\mathrm{H}_{2}$ as the carrier gas and with flame-ionization detection. Cholesterol content of diets was analysed by the same method. 
Table 5. The effect of sugar-beet fibre on ileostomy excretion in subjects given the basal diet with or without a supplement of $32 \mathrm{~g}$ Fibrex ${ }^{\circledR} \dagger / d_{+}$

\begin{tabular}{|c|c|c|c|c|}
\hline & \multicolumn{2}{|c|}{ Basal diet } & \multicolumn{2}{|c|}{ Basal diet $+32 \mathrm{~g}$ Fibrex $^{\text {B }}$} \\
\hline & Mean & SD & Mean & SD \\
\hline Wet weight $(\mathrm{g} / \mathrm{d})$ & 495 & 56 & 634 & $118^{* *}$ \\
\hline Dry weight $(g / d)$ & $44: 2$ & $15 \cdot 3$ & $66 \cdot 6$ & $14 \cdot 2^{* *}$ \\
\hline Fat $(\mathrm{g} / \mathrm{d})$ & $9 \cdot 4$ & $5 \cdot 4$ & $9 \cdot 6$ & $4 \cdot 5$ \\
\hline Net cholesterol $(\mathrm{mg} / \mathrm{d})$ & 297 & 298 & 451 & $371^{* *}$ \\
\hline Chenodeoxycholic acid (mg/d) & 294 & 51 & 224 & $120^{*}$ \\
\hline Cholic acid (mg/d) & 470 & 209 & 343 & $173^{* *}$ \\
\hline Total bile acid $(\mathrm{mg} / \mathrm{d})$ & 763 & 355 & 566 & $288^{* *}$ \\
\hline Net sterol excretion (mg/d) & 1060 & 533 & 1017 & 568 \\
\hline
\end{tabular}

Mean values were significantly different from those for the basal diet: ${ }^{*} P<0 \cdot 02,{ }^{* *} P<0 \cdot 01$.

$\dagger$ Swedish Sugar Co., Arlöv, Sweden.

\$ For details of diets and procedures, see Tables 1-4 and pp. 758-761.

\section{Calculations and statistical methods}

Values are given as means with their standard errors. Bile acid and fat excretion are reported as means for each dietary period. The period mean for cholesterol excretion minus dietary cholesterol is expressed as net cholesterol excretion. Mean bile acid plus net cholesterol excretion is termed net sterol excretion, which would be equivalent to the sterol balance concept used in long-term metabolic studies.

Comparisons of values from the two dietary periods were made by Wilcoxon's matchedpairs test. A computer package (MULREG 4·0, Idatron HB, Linköping, Sweden) was used for the actual calculations.

\section{RESULTS}

Ileostomy excretion values for the test diets are presented in Table 5. The addition of sugarbeet fibre increased wet weight by 139 (SE 45) g/d (28 (SE 9) \%; $P<0.01$ ). Dry weight increased by $22.4(\mathrm{SE} 1.7) \mathrm{g} / \mathrm{d}(51(\mathrm{SE} 4) \% ; P<0.01)$, whereas no significant increase in fat excretion was observed (mean increase 0.2 (SE 0.9) $\mathrm{mmol} / \mathrm{d} ; 2$ (SE 10) \%).

The sugar-beat-fibre-supplemented diet increased net cholesterol excretion by 154 (SE 28) mg/d (52 (SE 9) \%; P<0.01). Both chenodeoxycholic and cholic acid excretion were reduced, by $70($ SE 23$) \mathrm{mg} / \mathrm{d}(24(\mathrm{SE} 8) \% ; P<0.02)$ and 127 (SE 31) mg/d (27 (SE 15) \% ; $P<0.01)$ respectively. Only trace amounts of secondary bile acids were detected. Thus, total bile acid excretion was reduced by 197 (SE 51) $\mathrm{mg} / \mathrm{d}$ (26 (SE 15$) \% ; P<0.01$ ).

As the changes in net cholesterol and bile acid excretion opposed one another the total net sterol excretion was not significantly changed, there was a mean decrease of 43 (SE 67) $\mathrm{mg} / \mathrm{d}(4$ (SE 6) \%).

Wet weight concentration of bile acids decreased by 0.66 (SE $0 \cdot 15) \mathrm{mg} / \mathrm{g}$ on the sugarbeet-fibre diet $(42 \pm 10 \% ; P<0.01)$. Bile acid concentration on a dry weight basis decreased by $9 \cdot 18$ (SE 1.48$) \mathrm{mg} / \mathrm{g}(52$ (SE 8$) \% ; P<0.01)$.

Individual sterol excretion levels and diet responses are shown in Fig. 1. The day-to-day variation was low. The coefficient of variation for small bowel excretion of cholesterol in the present study was $16.6 \%$ for the basal diet period and $10.5 \%$ for the Fibrex ${ }^{\mathbb{R}}$ diet period (Table 6). Two patients complained of bloating during the high-fibre period. Their excretion patterns were the same as those for the rest of the group. None of the patients experienced discomfort during the low-fibre period. 


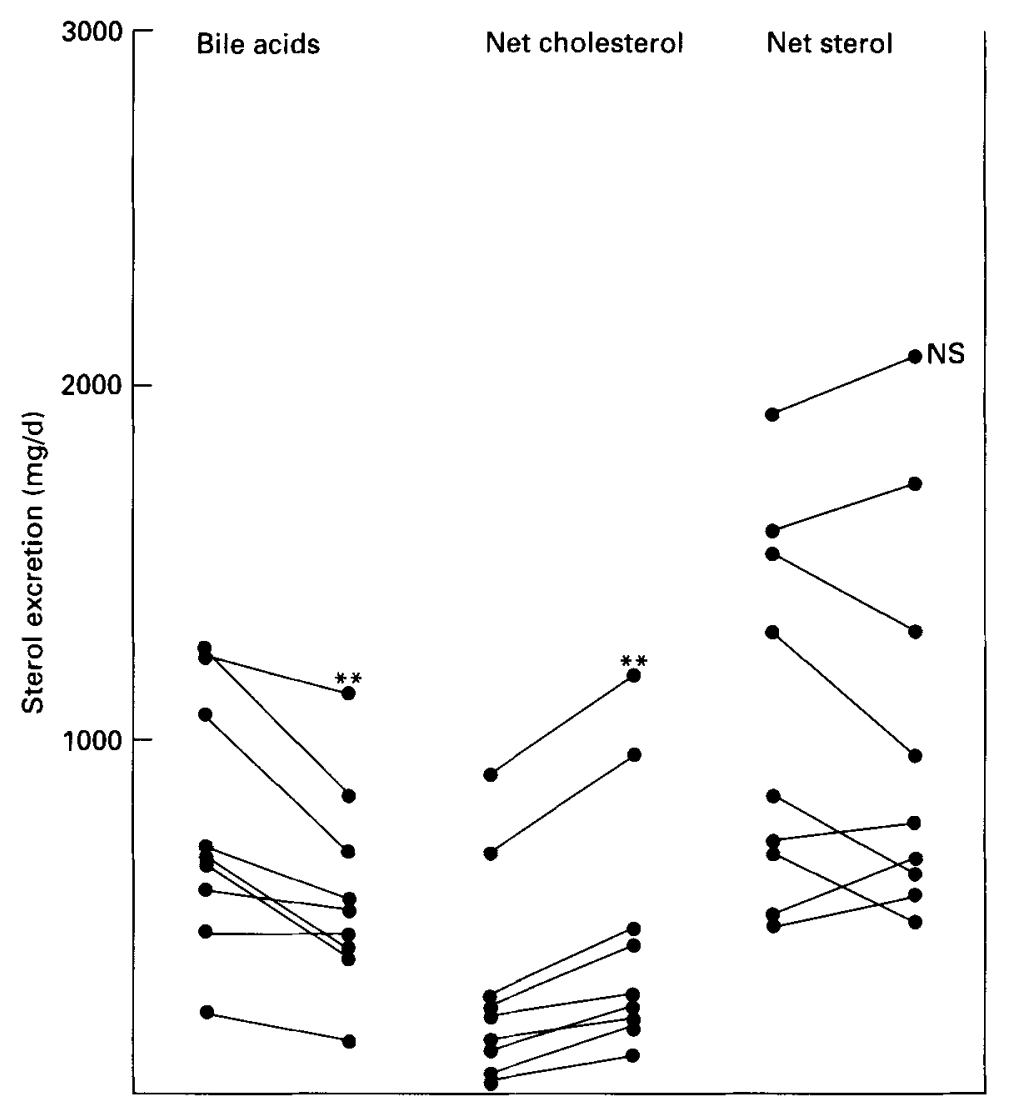

Diet... Basal Basal + Fibre Basal Basal + Fibre Basal Basal + Fibre

Fig. 1. The effect of sugar-beet fibre on individual sterol excretion in ileostomy subjects given the basal diet with or without 32 g Fibrex $^{\circledR}$ (Swedish Sugar Co., Arlöv, Sweden). For details of diets and procedures, see Tables 1-4 and pp. 758-761. Mean values were significantly different from those for the basal diet: ${ }^{*} P<0 \cdot 01$. NS, not significant.

Table 6. The effect of sugar-beet fibre on the excretion of cholesterol $(\mathrm{mg} / \mathrm{d})$ for each individual day of the study in ileostomy subjects given the basal diet with or without a supplement of $32 \mathrm{~g}$ Fibrex ${ }^{\mathrm{B} *} / \mathrm{d} \dagger$

\begin{tabular}{cccccc}
\hline & \multicolumn{2}{c}{ Basal diet } & & \multicolumn{2}{c}{ Basal diet +32 g Fibrex } \\
\cline { 2 - 3 } Subject no. & Day 1 & Day 2 & & Day 1 & Day 2 \\
\hline 1 & 453 & 422 & & 539 & 549 \\
2 & 468 & 508 & & 570 & 578 \\
3 & 534 & 508 & & 749 & 717 \\
4 & 1024 & 967 & & 1386 & 1218 \\
5 & 1311 & 938 & & 1604 & 1398 \\
6 & 327 & 327 & & 523 & 411 \\
7 & 540 & 597 & & 745 & 734 \\
8 & 429 & 370 & & 469 & 638 \\
9 & 336 & 443 & 467 & 498 \\
Mean & 602 & 564 & 784 & 749 \\
\hline
\end{tabular}

* Swedish Sugar Co., Arlöv, Sweden.

+ For details of diets and procedures, see Tables 1-4 and pp. 758-761. 


\section{DISCUSSION}

Sugar-beet fibre, which contains relatively large amounts of the viscous components pectin and hemicellulose $(70 \%)$, has been shown to have a hypocholesterolaemic effect (Hagander et al. 1988, 1989; Israelsson et al. 1988; Lampe et al. 1991; Tredger et al. 1991). Dietary supplementation of the habitual diet of hypercholesterolaemic women with $30 \mathrm{~g}$ Fibrex ${ }^{\mathbb{B}} / \mathrm{d}$, for 2 weeks (Israelsson et al. 1988) and an $8 \mathrm{~g}$ Fibrex ${ }^{(B)} / \mathrm{d}$ supplement to the habitual diet of non-insulin-dependent (NIDDM) subjects for 8 weeks (Hagander et al. 1988) gave a 4 and $6 \%$ decrease in total serum cholesterol respectively. In a later study by the same group of workers (Hagander et al. 1989), using NIDDM subjects, the addition of $40 \mathrm{~g} \mathrm{Fibrex}{ }^{\mathbb{8}} / \mathrm{d}$ gave an $8 \%$ decrease in total serum cholesterol compared with the habitual diet of the subjects, but no decrease when compared with a low-fibre diet. In a recent study on healthy men the addition of $20 \mathrm{~g} / \mathrm{d}$ of another sugar-beet-fibre product (Betafibre; British Sugar, Peterborough) to the habitual diet gave a $4.6 \%$ decrease in cholesterol (Tredger et al. 1991). In this study subjects with a high habitual intake of fat had a more pronounced hypocholesterolaemic response to sugar-beet fibre than subjects with a lower habitual intake of fat. The decrease in total serum cholesterol was also accounted for by a decrease in low-density-lipoprotein (LDL)-cholesterol. High-density-lipoprotein (HDL)-cholesterol remained unchanged in these studies (Hagander et al. 1988; Tredger et al. 1991) or was slightly increased (Israelsson et al. 1988; Hagander et al. 1989).

Dietary supplementation of a fibre-free liquid formula diet with $30 \mathrm{~g} / \mathrm{d}$ of yet another sugar-beet-fibre product (American Crystal Sugar Co, Moorhead, MN, USA) in a 3-week experiment in healthy men, gave a $12 \%$ decrease in total cholesterol, a $15 \%$ decrease in LDL-cholesterol but no change in HDL-cholesterol (Lampe et al. 1991).

In the present study we found increased cholesterol excretion and decreased bile acid excretion on addition of $32 \mathrm{~g}$ of a sugar-beet preparation Fibrex ${ }^{\circledR} / \mathrm{d}$ to a controlled diet with $4.3 \mathrm{~g}$ dietary fibre $/ \mathrm{d}, 31 \%$ energy $(\% \mathrm{E})$ from fat, $17 \% \mathrm{E}$ from protein and $52 \% \mathrm{E}$ from carbohydrate. The mean daily intake of cholesterol during the Fibrex ${ }^{\circledR}$ period was $315 \mathrm{mg}$. Thus, the mean increase in cholesterol excretion of $154 \mathrm{mg} / \mathrm{d}$ was about half that amount. Assuming the increased excretion of cholesterol reflects a decreased absorption of cholesterol and that the decreased excretion of bile acids is a secondary effect, the resulting effect on serum cholesterol could well be a small hypocholesterolaemic effect, in accordance with the findings in the previously mentioned studies. The hypocholesterolaemic effect could probably vary depending on which of the effects on sterol metabolism dominates.

Earlier studies with ileostomy subjects have shown that adding $15 \mathrm{~g}$ citrus pectin to the basal diet of six subjects induces a significantly increased short-term net excretion of cholesterol of $14 \%$, of bile acids of $35 \%$ and also an increased fat excretion (Bosaeus et al. 1986). The addition of $15 \mathrm{~g}$ citrus pectin/d to the diet has given similar effects in normal individuals (Kay \& Truswell, 1977).

The difference in effects between pectic substances in Fibrex ${ }^{\circledR}$ and pectin from other sources may be due to different chemical properties. The main differences between the Fibrex ${ }^{\circledR}$ pectic substances and commercial pectins, e.g. citrus pectin, relates to the solubility, degree of methylation, degree of acetylation and the presence of feruloyl groups. Differences in molecular-weight ranges may exist for the different types of soluble pectic substances but are difficult to ascertain in vivo, as deaggregation may occur on dilution. These differences may have implications for the different effects of the Fibrex ${ }^{\mathbb{R}}$ pectic substances $v$. the citrus or apple pectin.

Fibrex ${ }^{\mathbb{B}}$ contains $510 \mathrm{~g}$ pectic substances and hemicellulose $/ \mathrm{kg}$, i.e. the subjects were given $16 \mathrm{~g}$ pectic substances and hemicellulose $/ \mathrm{d}$. The degree of methylation is about $50 \%$. The pectin used in the study of Bosaeus et al. (1986) was a citrus pectin (Copenhagen Pectin Factor Ltd, Copenhagen, Denmark) with a degree of methylation of $71-74 \%$. Thus, the 
difference in degree of methylation might be one of the explanations for the different effects seen with Fibrex ${ }^{\circledR}$ and citrus pectin.

The ileostomy model offers a possibility to perform short-term studies on sterol excretion from the small bowel. The present study has shown that the variation in ileal excretion between two consecutive days after $1 \mathrm{~d}$ of adaptation is small. Therefore, studies using the ileostomy model can be performed with high precision in $2 \mathrm{~d}$, which is in accordance with our previous experience (Langkilde et al. 1990).

Binding and adsorption of bile acids to dietary fibre (Eastwood \& Hamilton, 1968; Kritchevsky, 1978) is often claimed to be the mechanism by which dietary fibre alters sterol balance. There is little evidence, however, for a chemical binding between bile acids and dietary fibre (Falk \& Nagyvary, 1982). Instead, the impaired absorption of sterols and lipids could be an effect of viscous entrapment due to the physical properties of the dietary fibre (Judd \& Truswell, 1982; Ebihara \& Schneeman, 1989). NMR spectroscopy studies have also shown that the interactions between pectin and bile acids are probably not due to chemical binding but to viscosity effects (Pfeffer et al. 1981). Dietary fibre does not only bind bile acids but also cholesterol and lipids (Eastwood \& Mowbray, 1976; Heaton, 1987; Story \& Lord, 1987). Thus, due to their physical properties different dietary fibres may have various effects in the small bowel giving different excretion patterns from the small intestine.

The mixed micellar structure is formed by cholesterol, bile acids and phospholipids to facilitate absorption from the gut. Sequestration of all the micellar components, in proportional amounts, have been shown for guar gum (Vahouny et al. 1980). Citrus pectin, with known serum cholesterol-lowering effect, has been shown to increase the excretion of both cholesterol, bile acids and fat from the gut (Kay \& Truswell, 1977; Bosaeus et al. 1986). However, addition of wheat bran, without a significant effect on serum cholesterol, has shown no effects on sterol or fat excretion in ileostomy studies (Bosaeus et al. 1986).

Studies in the rat have provided direct evidence that the hypocholesterolaemic potential of certain dietary fibres may be related, at least in part, to direct or indirect effects on the intestinal absorption of dietary and endogenous cholesterol (Vahouny et al. 1988). Thus, a similar mechanism could be suggested from the present study of sugar-beet fibre with (1) reduced absorption of cholesterol as the primary effect, resulting in a reduced substance supply to the liver and (2) secondarily a decreased excretion of bile acids, as they are formed by cholesterol in the liver.

Thus, from our ileostomy studies at least three different modes of action for dietary fibre on sterols and fat in the small bowel could be suggested: (1) decreased cholesterol absorption, with a secondary decrease in bile acid excretion, as seen with sugar-beet fibre, (2) interference with the mixed micellar structure, as seen with citrus pectin, (3) no effect on sterol excretion, as seen with wheat fibre. Thus, adding high-fibre foods to a diet may result in different excretion patterns and different effects on blood lipids due to the various effects of fibre products.

This work was supported by grants from the Swedish Medical Research Council (No. 19X570) and from the Swedish Sugar Co. The expert technical assistance of Ms Cecilia Lindgren and Ms Monica Johnsson is gratefully acknowledged.

\section{REFERENCES}

Abraham, Z. D. \& Mehta, T. (1988). Three-week psyllium-husk supplementation: effect on plasma cholesterol concentrations, fecal steroid excretion, and carbohydrate absorption in men. American Journal of Clinical Nutrition 47, 67-74.

Anderson, J. W., Deakins, D. A. \& Bridges, S. R. (1990). Soluble fiber. Hypocholesterolemic effects and proposed 
mechanisms. In Dietary Fiber. Chemistry, Physiology and Health Effects, pp. 339-363 [D. Kritchevsky, C. Bonfield and J. W. Anderson, editors]. New York: Plenum Press.

Anderson, J. W., Story, L., Sieling, B., Lin Chen, W. L., Petro, M. S. \& Story, J. (1984). Hypocholesterolemic effects of oat-bran or bean intake for hypercholesterolemic men. American Journal of Clinical Nutrition $\mathbf{4 0}$, $1146-1155$.

Asp, N.-G. (1990). Delimitation problems in definition and analysis of dietary fiber. In New Developments in Dietary Fiber. [I. Furda and J. Brine, editors]. New York: Plenum Press.

Bosaeus, I. \& Andersson, H. (1990). The effect of fat quality on intestinal steroid excretion. Näringsforskning 34, $51-55$.

Bosaeus, 1., Carlsson, N.-G., Sandberg, A.-S. \& Andersson, H. (1986). Effects of wheat bran and pectin on bile acid and cholesterol excretion in ileostomy patients. Human Nutrition 40C, 429-440.

Eastwood, M. A. \& Hamilton, D. (1968). Studies on the adsorption of bile salts to non-absorbed components of diet. Biochimica et Biophysica Acta 152, 165-173.

Eastwood, M. \& Mowbray, L. (1976). The binding of the components of mixed micelle to dietary fiber. American Journal of Clinical Nutrition 29, 1461-1467.

Ebihara, K. \& Schneeman, B. (1989). Interaction of bile acids, phospholipids, cholesterol and triglyceride with dietary fibers in the small intestine of rats. Journal of Nutrition 119, 1100-1106.

Falk, J. D. \& Nagyvary, J. J. (1982). Exploratory studies of lipid-pectin interactions. Journal of Nutrition 112 , 182-188.

Hagander, B., Asp, N.-G., Efendic, S., Nilsson-Ehle, P. \& Scherstén, B. (1988). Dietary fiber decreases fasting blood glucose levels and plasma LDL concentration in noninsulin-dependent diabetes mellitus patients. American Journal of Clinical Nutrition 47, 852-858.

Hagander, B., Asp, N.-G., Ekman, R., Nilsson-Ehle, P. \& Scherstén, B. (1989). Dietary fibre enrichment, blood pressure, lipoprotein profile and gut hormones in NIDDM patients. European Journal of Clinical Nutrition 43, 35-44.

Heaton, K. W. (1987). Dietary fibre and bile salts. Scandinavian Journal of Gastroenterology 22, Suppl. 129, $172-173$.

Heaton, K. W. \& Pomare, E. W. (1974). Effect of bran on blood lipids and calcium. Lancet i, 49-50.

Israelsson, B., Järnblad, G. \& Persson, K. (1988). Serum cholesterol reduced with Fibrex ${ }^{\mathrm{k}}$, a sugar-beet fibre preparation. In Dietetics in the 90s, pp. 167-170 [M. F. Moyal, editor]. London: John Libbey Eurotext Ltd.

Jenkins, D. J. A., Leeds, A. R., Newton, C. \& Cummings, J. H. (1975). Effect of pectin, guar gum and wheat fibre on serum cholesterol. Lancet i, 1116-1117.

Jenkins, D. J. A., Leeds, A. R., Slavin, B. \& Jepson, E. M. (1976). Guar gum in hyperlipidaemia. Lancet ii, 1351.

Johnson, I. T., Livesey, G., Gee, J. M., Brown, J. C. \& Wortley, G. M. (1990). The biological effects and digestible energy value of a sugar-beet fibre preparation in the rat. British Journal of Nutrition 64, 187-199.

Judd, P. A. \& Truswell, A. S. (1982). Comparison of the effects of high- and low-methoxyl pectins on blood and faecal lipids in man. British Journal of Nutrition 48, 451-458.

Kay, R. M. \& Truswell, A. S. (1977). Effect of citrus pectin on blood lipids and fecal steroid excretion in man. American Journal of Clinical Nutrition 30, 171-175.

Keenan, M. H. J., Belton, P. S., Matthew, J. A. \& Howson, S. J. (1985). A ${ }^{13}$ C-n.m.r. study of sugar-beet pectin. Carbohydrate Research 138, 168-170.

Kritchevsky, D. (1978). Influence of dietary fiber on bile acid metabolism. Lipids 13, 982-985.

Lampe, J. W., Slavin, J. L., Baglien, K. S., Thompson, W. O., Duane, W. C. \& Zavoral, J. H. (1991). Serum lipid and fecal bile acid changes with cereal, vegetable, and sugar-beet fiber feeding. American Journal of Clinical Nutrition 53, 1235-1241.

Langkilde, A. M., Andersson, H., Schweizer, T. F. \& Torsdottir, I. (1990). Nutrients excreted in ileostomy effluents after consumption of mixed diets with beans or potatoes. I. Minerals, protein, fat and energy. European Journal of Clinical Nutrition 44, 559-566.

McLean Baird, I., Walters, R. L., Davies, P. S., Hill, M. J., Drasar, B. S. \& Southgate, D. A. T. (1977). The effects of two dietary fiber supplements on gastrointestinal transit, stool weight and frequency, and bacterial flora, and fecal bile acids in normal subjects. Metabolism 26, 117-129.

Miettinen, T. A. \& Tarpila, S. (1977). Effect of pectin on serum cholesterol, fecal bile acids and biliary lipids in normolipidemic and hyperlipidemic individuals. Clinica Chimica Acta 79, 471-477.

National Food Administration (1988). Livsmedelstabeller. Swedish Food Composition Tables. Uppsala: Statens livsmedelsverk.

Pfeffer, P. E., Doner, L. W., Hoagland, P. D. \& McDonald, G. G. (1981). Molecular interactions with dietary fiber components. Investigation of the possible association of pectin and bile acids. Journal of Agricultural and Food Chemistry 29, 455-461.

Reddy, B. S., Watanabe, K. \& Sheinfil, A. (1980). Effect of dietary wheat bran, alfalfa, pectin and carrageenan on plasma cholesterol and fecal bile acid and neutral sterol excretion in rats. Journal of Nutrition 110 , $1247-1254$.

Rombouts, F. M. \& Thibault, J.-F. (1986). Feruloylated pectic substances from sugar beet pulp. Carbohydrate Research 154, 177-187.

Sandberg, A.-S., Andersson, H., Hallgren, B., Hasselblad, K. \& Isaksson, B. (1981). Experimental model for in 
vivo determination of dietary fibre and its effect on the absorption of nutrients in the small intestine. Journal of Nutrition 45, 283-294.

Stasse-Wolthuis, M., Hautvast, J. G. A. J., Hermus, R. J. J., Katan, M. B., Bausch, J. E., Rietberg-Brussard, J. H., Velema, J. P., Zondervan, J. H., Eastwood, M. A. \& Brydon, W. G. (1979). The effect of a natural highfiber diet on serum lipids, fecal lipids, and colonic function. American Journal of Clinical Nutrition 32, 1881-1888.

Story, J. A. \& Lord, S. L. (1987). Bile salts: In vitro studies with fibre components. Scandinavian Journal of Gastroenterology 22, Suppl. 129, 174-180.

Tornquist, H., Rissanen, A. \& Andersson, H. (1986). Balance studies in patients with intestinal resection. How long is enough? British Journal of Nutrition 56, 11-16.

Tredger, J. A., Morgan, L. M., Travis, J. \& Marks, V. (1991). The effects of guar gum, sugar beet fibre and wheat bran supplementation on serum lipoprotein levels in normocholesterolaemic volunteers. Journal of Human Nutrition and Dietetics 4, 375-384.

Truswell, A. S. \& Beynen, A. C. (1992). Dietary fibre and plasma lipids: Potential for prevention and treatment of hyperlipidemias. In Dietary Fibre - a Component of Food, pp. 295-332 [T. F. Schweizer and C. A. Edwards, editors]. London: Springer Verlag Ltd.

Truswell, A. S. \& Kay, R. M. (1975). Absence of effect of wheat bran on blood lipids. Lancet i, 922-923.

Walters, R. L., Mclean Baird, I., Davies, P. S., Hill, M. J., Drasar, B. S., Southgate, D. A. T., Green, J. \& Morgan, B. (1975). Effects of two types of dietary fibre on faecal steroid and lipid excretion. British Medical Journal 2, 536-538.

Vahouny, G. V., Satchithanandam, S., Chen, I., Tepper, S. A., Kritchevsky, D., Lightfoot, F. G. \& Cassidy, M. M. (1988). Dietary fiber and intestinal adaptation: effects on lipid absorption and lymphatic transport in the rat. American Journal of Clinical Nutrition 47, 201-206.

Vahouny, G. V., Tombes, R., Cassidy, M. M., Kritchevsky, D. \& Gallo, L. L. (1980). Dietary fibers: V. Binding of bile salts, phospholipids and cholesterol from mixed micelles by bile acid sequestrants and dietary fibers. Lipids 15, 1012-1018.

van der Kamer, J. H., ten Bokkel Huinink, H. \& Weyers, H. A. (1949). Rapid method for the determination of fat in feces. Journal of Biological Chemistry 177, 347-355. 